\title{
EL PRINCIPIO JURÍDICO-POLÍTICO DE LA DIVISIÓN DEL PODER Y LOS ÓRGANOS CONSTITUCIONALES AUTÓNOMOS
}

\author{
The juridical and political principle of division of power \\ and constitutional autonomous organisms
}

\section{Juan Antonio RODRÍGUEZ CORONA}

A la memoria siempre grata de mis abuelos David Corona y J. Apolinar Rodríguez.

\begin{abstract}
Sumario:
I. Introducción. II. Perspectiva histórico-política del principio de división de poder. III. División del Poder vs Órganos Constitucionales Autónomos. IV. Los Órganos Constitucionales en México y su evolución constitucional. V. Conclusiones.
\end{abstract}

Resumen: La existencia del principio de división del poder en toda Constitución implica que éste se divide para su ejercicio en tres funciones que caracterizan al Estado moderno, a saber: legislativa, ejecutiva y judicial. Sin embargo, en nuestro país, con la multiplicación de órganos constitucionales autónomos se asoma lo que podría ser una crisis entre éstos y aquél. El reto de armonizar las potestades conferidas a los poderes constituidos con las facultades que se les confieren a las autonomías constituye, sin duda, uno de los compromisos de nuestro constitucionalismo contemporáneo.

Palabras clave: Estado, Constitución, División de poderes, Poderes constituidos, Órganos constitucionales autónomos.

Abstract: In every Constitution, the existence of the principle of division of power implies its dissection in three functions that characterize the modern state, namely: legislative, executive and judicial. Nevertheless, the proliferation of constitutional autonomous organisms in our country raises the possibility of a crisis among these and the former. It is a challenge of modern constitutionalism to harmonize the attributions bestowed upon the constitutional branches with those vested in autonomous bodies.

Keywords: State, constitution, division of powers, constitutional branches, constitutional autonomous bodies.

\footnotetext{
${ }^{1}$ Profesor de la División de Derecho, Política y Gobierno de la Universidad de Guanajuato.
} 


\section{I.INTRODUCCIÓN}

Se ha decidido que el viejo Leviatán entre al quirófano y se le practique una cirugía que le permita ser verdaderamente eficaz y cumplir con los propósitos que justifican su existencia. Así, el concepto y estructura del Estado — herencia del siglo XVIII—, se encuentra inmerso en una vorágine de ajustes y cambios que bien a bien nadie puede prever cómo habrá de plasmarse su trazo final. Uno de los pilares constitutivos del Estado moderno - hoy a debate-, es el principio de división del poder. Se reconoce que su esencia data desde el pensamiento grecolatino y se institucionalizó a partir de la Revolución Francesa como conquista política de la burguesía revolucionaria. A partir de entonces, prácticamente en todo Occidente no existe una Constitución que no lo prevea a fin de que, precisamente por la proyección de un poder político fragmentando, se logre tutelar la libertad de la persona humana. Empero, en las últimas décadas esta tesis se encuentra en crisis. La causa es la aparición — vía reforma constitucional—, de un elenco de instituciones u órganos denominados “constitucionalmente autónomos”. Es decir, están en la propia Constitución pero guardan celosa autonomía respecto de los poderes constituidos, los cuales por cierto, representaban hasta no hace mucho el recipiente natural de las funciones clásicas en la que se desenvuelve el poder político del Estado. Hoy esto ya no es así. ¿Cómo se explica la aparición y multiplicación de estos órganos en nuestro sistema constitucional? ¿Qué atribuciones se les han encomendado? ¿Qué vínculo jurídico-político tienen con los poderes constituidos? ¿Cómo armonizar su existencia y potestades frente a los poderes ejecutivo, legislativo y judicial?. A la respuesta de cada una de estas interrogantes se encamina esta modesta colaboración. Si los expertos de estos temas encuentran alguna luz en ellas, el autor se sentirá satisfecho con su tarea.

\section{PERSPECTIVA HISTORICO-POLÍTICA DEL PRINCIPIO DE DIVISIÓN DE PODER}

Aristóteles fue quien expresó la necesidad de dividir el poder político desde su mirador de la Ciudad-Estado en la Grecia antigua. Siglos después, ya con la creación del Estado Moderno, éste se dividió precisamente en tres poderes a fin de proyectar un equilibrio entre las distintas funciones del Estado y, con ello, garantizar la sana relación entre el poder temporal y los gobernados a fin de diluir, en lo posible, el fantasma del absolutismo político. ${ }^{2}$

Francia daría puntual cuenta de este histórico hecho. El espíritu insurgente y liberal de su burguesía -inspirado en Montesquieu, Voltaire, Diderot, Rousseau, D'Alambert, entre otros destacadísimos liberales-, cristalizaría de manera categórica e inequívoca en el principio de división del poder como único medio de acabar con el poder absoluto del Monarca. Así, la Asamblea Nacional Constituyente, en su sesión de 18 de agosto de 1789, determinó

\footnotetext{
2 "Locke encontró las garantías constitucionales de la limitación del poder estatal en la famosa doctrina de la separación de poderes. Ya los griegos habían hecho distinciones en la actividad estatal, subrayando que ésta no era unitaria, sino que tenía aspectos diferentes. Así, Aristóteles señalaba que una cosa era la actividad deliberativa de las asambleas y otra la ejecución de sus órdenes. Ahora bien, Locke, constitucionaliza la división o distinción de las actividades del estado, es decir, establece diversos organismos especializados para cada una de las actividades que, según él, son tres; a saber: el poder legislativo, el poder ejecutivo y el poder federativo. GINER, Salvador, Historia del pensamiento social, Ediciones Ariel, Barcelona, España, 1966, pp. 271-272.
} 
- a propuesta del Conde de Mirabeau - ${ }^{3}$ que la declaración de Derechos sería parte de la nueva Constitución francesa y, en su correspondiente sesión del 27 del propio mes, aprobó la Declaración de los Derechos del Hombre y del Ciudadano, la cual en su artículo XVI establecería lo siguiente: “Toda sociedad en la cual la garantía de los derechos no esté asegurada, ni determinada la separación de los poderes, carece de constitución”.

En este tránsito nuestra Carta Política — siguiendo la tradición del pensamiento liberalburgués_-, prevé en su artículo 49 que el "Supremo Poder de la Federación se divide para su ejercicio en Legislativo, Ejecutivo y Judicial. No podrán reunirse dos o más de estos Poderes en una sola persona o corporación, ni depositarse el Legislativo en un individuo, salvo el caso de facultades extraordinarias al Ejecutivo de la Unión, conforme a lo dispuesto en el artículo 29. En ningún otro caso, salvo lo dispuesto en el segundo párrafo del artículo 131, se otorgarán facultades extraordinarias para legislar"; 4 esto significa que el Constituyente Originario adoptó como principio básico de organización del poder político la clásica división de funciones propuesto por el pensamiento revolucionario. Empero, este postulado que en principio reconoce sus raíces en la indispensable necesidad de limitar el poder político y, con ello, establecer un dique a favor de la libertad del individuo, hoy enfrenta diversos retos que en su origen, como resulta natural y comprensible, jamás fueron considerados.

Por nuestra parte, refrendamos la tesis que explica que la división del poder público no ha sido ni es — para decirlo en palabras de Tena Ramírez-, "un principio doctrinario, logrado de una sola vez y perpetuado inmóvil; sino una institución política, proyectada en la Historia"; en tal sentido, en todo el mecanismo constitucional que explica nuestro sistema jurídico, podemos advertir cómo es que no son pocos los supuestos en que se vinculan distintas potestades públicas de los tres poderes de la Unión a fin de dotar de equilibrio y eficacia plena un determinado acto jurídico-constitucional.

Se sabe pues que no existe preeminencia jurídica de un poder respecto de otro; sin embargo, en los hechos, esto dista mucho de ser así, puesto que es fácil registrar cómo es que no son pocos los procesos jurídicos en los que se presenta - en esta lógica de pesos y contrapesos-, mayor relieve de una función en contraste con otra. A modo de ejemplo, puedo citar la aprobación del presupuesto de egresos de la federación; a mi parecer, en este acto existe a favor de la Cámara de Diputados un poder de decisión que - a título de facultad exclusiva-, claramente subordina desde el punto de vista jurídico y político no sólo al Poder Ejecutivo sino al Estado en su conjunto, en virtud de que es precisamente con la aprobación

\footnotetext{
3 “...Ya en la sesión del 23 de junio, el rey había ordenado a los representantes populares separarse inmediatamente. En aquel instante solemne se escuchó al Conde de Mirabeau, quien elevando la voz dijo: ...¿Quién da esta orden? Vuestro mandatario. ¿Quién os da leyes imperiosas? Vuestro mandatario, él, que debe recibirlas de vosotros, de nosotros, señores, que estamos investidos de un sacerdocio político inviolable...". BRISEÑO SIERRA, Humberto, El artículo 16 de la Constitución mexicana, UNAM, México, 1967, p. 53.

4 "La tesis mexicana, y que han seguido todas las Constituciones de este país, salvo en 1814, tal como hemos señalado, consiste en que no hay división de poderes, sino que existe un solo poder: el supremo poder de la Federación, que se divide para su ejercicio; así, lo que está dividido es el ejercicio del poder. Cada rama del poder — los poderes constituidos: Legislativo, Ejecutivo y Judicial — es creada por la propia C, la que les señala expresamente sus facultades, su competencia; lo que no se les atribuye no lo podrán ejercer”. CARBONELL, Miguel [coord.], Diccionario de Derecho Constitucional, $3^{\mathrm{a}}$. ed., México, Porrúa-UNAM, México, 2009, t. II, p. 552.
} 
de este instrumento de política económica como se salva durante toda la anualidad el gasto público del Estado.

Otro supuesto en el que se presenta la preeminencia de un poder a diferencia de otro - en este caso el Poder Ejecutivo sobre el Legislativo-, es precisamente en la facultad de veto; y, en el caso del Poder Judicial de la Federación, baste decir que es precisamente en este poder en donde reposa la defensa última de la Constitución. ${ }^{5}$

No pretendo agobiar al lector con los diversos procedimientos jurídico-constitucionales en los que, a mi parecer, descuella un poder en sus vínculos con los otros dos; por el contrario, mi propósito ha sido el dejar patente que, en efecto, el sistema de pesos y contrapesos que en sí mismo implica la teoría de la división del poder no ha sido jamás ni lo puede ser en modo alguno, jurídica y políticamente absoluto. ${ }^{6}$

Así lo ha manifestado la Suprema Corte de Justicia de la Nación en el siguiente criterio que reproduzco in extenso por su importancia toda vez que se proyecta desde nuestro Alto Tribunal los principios que la doctrina ha desarrollado durante largo tiempo:

DIVISIÓN DE PODERES. EL QUE ESTE PRINCIPIO SEA FLEXIBLE SÓLO SIGNIFICA QUE ENTRE ELLOS EXISTE UNA COLABORACIÓN Y COORDINACIÓN EN LOS TÉRMINOS ESTABLECIDOS, PERO NO LOS FACULTA PARA ARROGARSE FACULTADES QUE CORRESPONDEN A OTRO PODER, SINO SOLAMENTE A AQUELLOS QUE LA PROPIA CONSTITUCIÓN LES ASIGNA. El artículo 49 de la Constitución Política de los Estados Unidos Mexicanos establece que el Supremo Poder de la Federación se divide para su ejercicio en Legislativo, Ejecutivo y Judicial y que no podrán reunirse dos o más de estos poderes en un solo individuo o corporación. Sin embargo, ha sido criterio reiterado de esta Suprema Corte que la división funcional de atribuciones que establece dicho numeral no opera de manera rígida, sino flexible, ya que el reparto de funciones encomendadas a cada uno de los poderes no constituye una separación absoluta y determinante, sino por el contrario, entre ellos se debe presentar una coordinación o colaboración para lograr un equilibrio de fuerzas y un control recíproco que garantice la unidad política del Estado. Como se advierte, en nuestro país la división funcional de atribuciones no opera de manera tajante y rígida identificada con los órganos que las ejercen, sino que se estructura con la finalidad de establecer un adecuado equilibrio de fuerzas, mediante un régimen de cooperación y coordinación que funcionan como medio de control recíproco, limitando y evitando el abuso en el ejercicio

\footnotetext{
5 A partir de la reforma Constitucional en materia de Derechos Humanos, publicada en el DOF el 10 de junio de 2011, se modificó el esquema en el que los órganos jurisdiccionales deben ejercer el denominado control de constitucionalidad. Ergo, a partir de la referida fecha, todas las autoridades de orden público, en atención a sus propias órbitas de competencia, tienen el deber de promover, proteger, respetar y tutelar los derechos humanos reconocidos en nuestra propia Constitución y en los Tratados Internaciones en los que México sea parte.

6 "Las nuevas relaciones entre poderes, desarrolladas a partir de la alternancia, han estado marcadas por dos características: la primera consiste en los desencuentros entre el Congreso y el Ejecutivo, que han bloqueado las reformas estructurales, han asumido la polarización política y electoral y han convertido sus relaciones en enfrentamientos partidarios. La segunda, derivada directamente de la anterior, es que ante esa falta de colaboración, la Suprema Corte de Justicia paulatinamente se ha convertido en el árbitro de los actores e instituciones políticas, para lo cual no siempre ha aplicado la ley de manera objetiva o, lo que ha sido aún más polémico, con un extremo rigor técnico que no resuelve los conflictos". HERNÁNDEZ RODRÍGUEZ, Rogelio, Hacia un nuevo equilibrio en la relación de poderes, Los grandes problemas de México, México, El Colegio de México, A.C., 2012, t. IV, p. 233.
} 
del poder público, garantizando así la unidad del Estado y asegurando el establecimiento y preservación del estado de derecho. Por su parte, el artículo 133 de la Constitución Federal consagra el principio de supremacía, que impone su jerarquía normativa a la que deben sujetarse todos los órganos del Estado y todas las autoridades y funcionarios en el ejercicio de sus atribuciones, por lo que, el hecho de que la división de poderes opere de manera flexible sólo significa que entre ellos existe una colaboración y coordinación en los términos establecidos, pero no los faculta para arrogarse facultades que corresponden a otro poder, sino solamente aquellos que la propia Constitución les asigna. De este modo, para que un órgano ejerza ciertas funciones es necesario que expresamente así lo disponga la Constitución Federal o que la función respectiva resulte estrictamente necesaria para hacer efectivas las facultades que le son exclusivas por efectos de la propia Constitución, así como que la función se ejerza en los casos expresamente autorizados o indispensables para hacer efectiva la facultad propia. ${ }^{7}$

\section{DIVISIÓN DE PODERES VS ÓRGANOS CONSTITUCIONALES AUTÓNOMOS}

Asentado el procedimiento de permanente vinculación política entre los tres poderes formales del Estado, es posible mencionar que en los últimos años nuestro constitucionalismo se ha caracterizado por establecer lo que en la teoría y en la práctica se conocen como órganos constitucionales autónomos. ${ }^{8}$ La mayoría de los estudiosos de este fenómeno sostienen que su aparición en la vida política del Estado mexicano ha venido a "enriquecer la doctrina de la división de poderes”, en razón de que, derivado de las características que acompañan a estos órganos, precisamente los ubican a la par de los conocidos poderes constituidos. ${ }^{9}$ En ese sentido, podemos anotar como elementos esenciales de los órganos autónomos los siguientes:

i) Son creados directamente por la norma Constitucional;

ii) Ejercen potestades públicas previstas directamente desde la Constitución y relacionadas con los fines del Estado;

iii) No reflejan dependencia orgánica o funcional con ninguno de los poderes constituidos;

iv) Poseen autonomía técnica, financiera, orgánica y funcional; y

7 Jurisprudencia P./J. 78/2009, emitida por el Tribunal Pleno, publicada en el Semanario Judicial de la Federación y su Gaceta, Novena Época, t. XXX, julio de 2009, p. 1540.

8 "Los órganos constitucionales autónomos surgen sobre todo a partir de la segunda guerra mundial, aunque fueron ya teorizados por Georg Jellinek y Santi Romano desde finales del siglo XIX. La existencia de dichos órganos supone un enriquecimiento de las teorías clásicas de la división de poderes que postulaban que dentro de un Estado solamente había tres funciones: la legislativa, la ejecutiva y la judicial". CARBONELL, Miguel, [coord.], Op. Cit., nota 4, p. 1053.

9 Disiento de Narciso Sánchez G., cuando afirma: “Con la creación y funcionamiento de los organismos constitucionales autónomos, se ha dado un paso muy relevante en la vida institucional de México, con lo que se demuestra que ha evolucionado el principio de la división de Poderes, lo cual ya no puede verse de una manera tan rígida como ocurrió en el pasado; por el contrario, es una manera de fortalecer dicha teoría que está contemplada en la misma Constitución Política Federal... no obstante, insisto en que se requiere hacer algunas adecuaciones a ese principio que ya está desfasado". Distribución del poder público y el sistema presidencial, México, Porrúa, 2011, pp. 155-156. 
v) Guardan una paridad de rango respecto de los demás poderes de la Unión.

El propio Poder Judicial de la Federación —dentro de los criterios que sobre el particular ha emitido-, comprende y participa de los argumentos que la doctrina ha elaborado sobre las autonomías:

ÓRGANOS CONSTITUCIONALES AUTÓNOMOS. SUS CARACTERISTICAS. Con motivo de la evolución del concepto de distribución del poder público se han introducido en el sistema jurídico mexicano, a través de diversas reformas constitucionales, órganos autónomos cuya actuación no está sujeta ni atribuida a los depositarios tradicionales del poder público (Poderes Legislativo, Ejecutivo y Judicial), a los que se les han encargado funciones estatales específicas, con el fin de obtener una mayor especialización, agilización, control y trasparencia para atender eficazmente las demandas sociales; sin que con ello se altere o destruya la tradicional doctrina de la división de poderes, pues la circunstancia de que los referidos organismos guarden autonomía e independencia de los poderes primarios, no significa que no formen parte del Estado mexicano, ya que su misión principal radica en atender necesidades torales tanto del Estado como de la sociedad en general, conformándose como nuevos organismos que se encuentran a la par de los órganos tradicionales. Ahora bien, aun cuando no existe algún precepto constitucional que regula la existencia de los órganos constitucionales autónomos, éstos deben tener: a) estar establecidos y configurados directamente en la Constitución; b) mantener con los otros órganos del Estado relaciones de coordinación; c) contar con autonomía e independencia funcional y financiera; $y, d$ ) atender funciones coyunturales del Estado que requieran ser eficazmente atendidas en beneficio de la sociedad. ${ }^{10}$

Por lo tanto, esta tesis en principio podría ser cierta. Sin embargo, refiriéndonos a nuestro país, la reciente y acentuada creación de órganos autónomos ha venido, por una parte, a fortalecer el argumento que establece que la división de poderes se enriquece cuando la asunción de nuevas potestades por parte del Estado Mexicano se materializa con el establecimiento de instituciones públicas de naturaleza autónoma; empero, en contraste, también podría afirmarse que en no pocos casos la creación de este tipo de instituciones se ha explicado y explica por razones fundamentalmente políticas que en modo alguno se vinculan con la consolidación del poder público.

Esto no quiere decir, de ninguna manera, que con el devenir del tiempo, estos órganos carezcan de legitimidad en nuestro ordenamiento jurídico. ${ }^{11}$ Es evidente hoy en día la importantísima función que realizan la inmensa mayoría de ellos; v.gr., el Banco de México, la Comisión Nacional de los Derechos Humanos o el Instituto Nacional de Estadística y Geografía, entre otros. Sin embargo, somos conscientes de que su génesis no siempre se explica

\footnotetext{
${ }_{10}$ Jurisprudencia P./J. 12/2008, emitida por el Tribunal Pleno, publicada en el Semanario Judicial de la Federación y su Gaceta, Novena Época, t. XXVII, febrero de 2008, p. 1871.

11 “Ciertamente, los órganos autónomos previstos en la Constitución — los que ya lo están y los que pueden estarlo en lo futuro - son de la mayor importancia dentro del entramado constitucional mexicano, así como una fuente importante de innovaciones para incorporar al texto de la carta magna con miras a su perfeccionamiento. Su éxito y posibilidad operativa real depende del buen diseño institucional que se realice y del talante de sus integrantes (como bien se ha demostrado en el caso de la Comisión Nacional de los Derechos Humanos, dirigida en sus primeros años por brillantes juristas)”. CARBONELL, Miguel, Constitución, reforma constitucional y fuentes del derecho en México, México, Porrúa-UNAM, 2000, p. 64.
} 
por una decisión de alta técnica-constitucional sino que, en algunos casos, responden a una elemental coyuntura electoral o de negociación político-partidista encaminada — se dice-, a agilizar la acción política del Estado.

"La autonomía e independencia del IFAI y el INE son presa de una rebatinga partidista. La conformación del pleno de comisionados del nuevo Instituto Federal de Acceso a la Información y Protección de Datos, así como de los consejeros electorales de lo que será el Instituto Nacional Electoral, está marcada por la opacidad, la discrecionalidad en los criterios y la lucha entre los partidos políticos. Definidas las 11 quintetas con 50 nombres para integrar el órgano electoral, ahora las disputas partidistas para colocar a sus candidatos afines están impactando en la definición de quién presidirá y quienes integrarán el Instituto. La decisión será tomada por los líderes de bancadas en Cámaras de Diputados en reuniones privadas en la Junta de Coordinación Política. En la negociación, Acción Nacional insiste en rearmar las quintetas y colocar a un aspirante afín en la lista para presidente. El PRI y el PRD señalaron que la petición del PAN es difícil de cumplir, mientras que los albiazules expresaron su intención de no votar a favor de la planilla que se presente y forzar la insaculación del presidente, ya que se necesita el acuerdo de las dos terceras partes para los nombramientos. Ayer un grupo de 40 organizaciones sociales y 60 personalidades hizo público un llamado a la Cámara baja para que evite la designación por reparto de cuotas partidistas. "Estamos muy preocupados y no queremos que los consejeros del INE tengan ADN de los partidos. Ya tuvimos la experiencia con (el ex consejero) Sergio García Ramírez", dijo Clara Jusidman, presidenta de Incide Social. En cuanto al nombramiento de los siete miembros del IFAI, ayer las comisiones unidas del Senado encargadas del proceso aprobaron los criterios para escoger entre los 158 aspirantes que cumplieron con los requisitos y que deberán comparecer a partir del próximo lunes. En dicha reunión, Pablo Escudero, presidente de la Comisión Anticorrupción aceptó que el valor que le dé cada legislador a los criterios para calificar a los aspirantes será subjetivo, pues alguien podrá valorar más la experiencia o que "hablen otro idioma" sobre los méritos académicos. Juan Pablo Guerrero, ex miembro del IFAI, alertó que, ante la falta de un método efectivo, van a imperar las arbitrariedades y la discrecionalidad en la integración del Instituto". 12

IV. LOS ÓRganos CONSTITUCiONALES AUTÓNOMOS EN MÉXICO Y SU EVOLUCióN CONSTITUCIONAL

En los últimos lustros, nuestro régimen constitucional ha sido objeto de una serie de reformas con el propósito de incorporar las autonomías constitucionales. A mi juicio esta tendencia es preocupante; me explico: se trata de una inercia que no por sus propias pausas, paréntesis silenciosos y hasta en ocasiones dilatados, resulta menos inquietante y que consiste precisamente en sustraer - bajo el argumento de que no se ha cumplido o se ha cumplido de modo insuficiente, parcial o ineficaz - de los poderes formales del Estado alguna o varias

\footnotetext{
${ }^{12}$ SALAZAR, Claudia. et al., "Disputan partidos órganos autónomos”, Reforma, México, D.F., año XXI, número 7,397, marzo 2014, p. 1.
} 
atribuciones y encomendárselas a una nueva y diferente institución que, en la mayoría de los casos, reviste la naturaleza jurídica de una autonomía constitucional. ${ }^{13}$

De modo particular, podemos decir que este fenómeno jurídico-político se presenta, en la gran mayoría de las veces, con la amputación de una potestad del Poder Ejecutivo para trasladarla sin más a un órgano constitucionalmente autónomo con el innegable y evidente debilitamiento de dicho poder y, por otra parte, la cuestionable multiplicidad de este tipo de órganos que se colocan, como es sabido, a la par de las tradicionales funciones constituidas creando con ello un "constitucionalismo de escape" que implique el continuo desaire hacia los poderes clásicos previstos ya en la Constitución y la legitimidad jurídico-política que éstos representan en aras de construir y fortalecer autonomías constitucionales - en todos los niveles de gobierno-, sin los indispensables controles democráticos y los mecanismos esenciales para la transparencia en el ejercicio del servicio público y la rendición de cuentas vinculada indisolublemente a éste.

De lo anterior, puedo afirmar sin titubeos, que en nuestro país existe una sostenida tendencia a tratar de resolver nuestra complejísima realidad jurídica, social, política y económica a través de la creación de autonomías.

La gran interrogante que debemos plantearnos es si efectivamente con la creación de estos órganos de naturaleza autónoma se consolida el Estado mexicano o, por el contrario, simple y llanamente se debilita su estructura formal en razón de que se eliminan facultades previstas a favor de los poderes clásicos en aras de crear una nueva burocracia que, bajo el argumento de que por el sólo hecho de ser autónomos, se garantiza su eficacia, honestidad y funcionalidad.

Lo explica así Diego Valadés:

"Conforme a la doctrina clásica, en capítulos sucesivos la Constitución define esos poderes como legislativo, ejecutivo y judicial. Empero, diversas reformas se han separado de esa concepción y desde hace algunos años se viene incluyendo una serie de órganos a los que se conoce como "constitucionales" porque figuran en el texto constitucional y ejercen potestades públicas pero no forman parte de los poderes a que se refiere el artículo 41. La Constitución es taxativa en cuanto a la enunciación de los poderes a través de los cuales el pueblo ejerce su soberanía. En tanto que los "órganos constitucionales" son autónomos de esos poderes resulta que hay zonas del Estado substraídas al dominio soberano del pueblo...El único rasgo común de esos organismos es que son autónomos. Esto significa que no dependen de nadie y por ende ante nadie responden del ejercicio de sus funciones, pues esto supuestamente afectaría su autonomía. El diseño de los nuevos órganos constitucionales y su autonomía ante los poderes a través de los cuales el pueblo ejerce su soberanía, son una distorsión constitucional que se origina en la desconfianza acerca de cómo se practica el poder en México. La ausencia de controles políticos eficaces generó esta deformación. Como consecuencia una parte voluminosa de la burocracia se ha autonomizado de los órganos con relación a los cuales los ciudadanos tenemos derecho de decisión. La soberanía popular, piedra angular de todo sistema constitucional demo-

\footnotetext{
13 "Los órganos constitucionales autónomos deben ser distinguidos de los llamados "órganos auxiliares" u "órganos de relevancia constitucional". Estos últimos compartirían algunas, pero no todas, las características que definen a los órganos constitucionales autónomos. Normalmente, la característica que le falta es la que tiene que ver con la no inclusión en la estructura orgánica de alguno de los poderes tradicionales". CARBONELL, Miguel [coord.], Op. Cit., nota 4, pp. 1054-1055.
} 
crático, ya no es relevante para la distribución del poder. Progresivamente se está acentuando la construcción de una Constitución privada dentro de la Constitución pública que impide el control político y social sobre grandes áreas vinculadas con el bienestar, con la economía, con los servicios públicos, con las libertades y con la seguridad nacional. El pueblo no ejerce su soberanía a través de esos órganos, por lo que puede decirse que está en proceso de formación una nueva expresión soberana: la burocrática”. ${ }^{14}$

Evidentemente, cada una de estas autonomías responde a un perfil jurídico-político distinto encaminado a conformar la voluntad política del Estado en su conjunto; es decir, cada una de ellas explica y justifica su existencia y actuación a partir de sus propios vínculos, su cercanía con el gobernado o con el propio poder público y la manera en que éste se regula. De ahí que debamos entender que no podemos evaluarlas o analizarlas a partir de una sola lente. Sin embargo, con independencia de sus particularidades, lo cierto es que en todos los casos se presentan como eficaz modelo de salvaguarda de derechos fundamentales, instituciones de verdadero control o regulación y de genuina imparcialidad, objetividad y buena fe.

En efecto, un hecho que debe llamar nuestra atención es precisamente que el origen que en no pocos casos determinó la creación de estos órganos fue justamente el desgaste que determinada atribución reflejaba en sede formal, la cual, como apuntamos en líneas precedentes, por regla general ha sido la del Poder Ejecutivo. Sin embargo, este mismo deterioro hoy lo acusan ciertas autonomías que nacieron precisamente para dotar de legitimidad a una tarea pública de suyo disminuida. Un claro ejemplo de ello lo constituye la fulminante desaparición del Instituto Federal Electoral (IFE) versus el hoy Instituto Nacional Electoral (INE).

La crisis de legitimidad jurídica-política de un órgano constitucionalmente autónomo fue resuelta con la creación precisamente de otra autonomía constitucional, lo cual nos lleva necesariamente a la reflexión de si realmente se trata de un problema de diseño institucional o si sólo se proyecta una solución gatopardista o lampedusiana que refleje en nuestro tiempo lo que precisamente le sucedió a don Fabrizio Corbera y familia en la Italia del siglo XIX, cuando éstos advierten con gran olfato político que ante el arribo de un nuevo gobierno en Sicilia, la aristocracia que ellos representaban debía adaptarse a los nuevos vientos políticos a fin de conservar su status quo. Su filosofía se sintetiza en la siguiente frase: "Si queremos que todo siga como está, es necesario que todo cambie".

Podemos citar también el caso de la Comisión Nacional de los Derechos Humanos $(\mathrm{CNDH})$, la cual se ha visto en los últimos años seriamente cuestionada por miembros de organizaciones no gubernamentales que han manifestado expresamente su inconformidad con la falta de atención y compromiso de esta autonomía para con las víctimas y desaparecidos de los años recientes en nuestro país.

Incluso, existe una corriente de opinión que señala que la Comisión Nacional de los Derechos Humanos se encuentra distante de lo que debería ser su centro de gravedad: la atención a minorías vejadas, migrantes en permanente riesgo, periodistas amenazados en amplísimas zonas del país, etcétera. Con un presupuesto público sólido y una burocracia abultada, se cuestiona si existe o no un compromiso genuino que la lleve a emitir recomendaciones que - siendo evidentemente incómodas para su destinatarios-, reflejen que por encima de cualquier consideración política está la importancia de que la sociedad denuncie, de que la

14 “La soberanía burocrática”, Reforma, México, D.F., año XXI, número 7,457, mayo 2014, p. 12. 
propia Comisión fortalezca sus investigaciones y, en su caso, se pronuncie institucionalmente a fin de no dejar ninguna sombra de impunidad respecto a las violaciones de derechos humanos que se cometen desde el poder público.

Al respecto, José de Jesús Gudiño Pelayo afirma: "La Comisión Nacional de Derechos Humanos es hija de las circunstancias políticas nacionales e internacionales que se vivieron a principios del sexenio de 1988-1994. Una elección presidencial sumamente cuestionada, al grado de que aún hoy se discute en algunos círculos políticos importantes respecto a qué candidato de aquella contienda electoral ganó real y efectivamente dicha elección. A mi juicio, esa discusión hace mucho tiempo que perdió su razón de ser, hace mucho tiempo que carece de sentido y de oportunidad; sin embargo, es un hecho comprobable que hay quien todavía polemiza al respecto. Esto provocó, unido a muchos otros factores que no viene al caso ni es oportuno analizar en el breve espacio de este estudio, una imagen presidencial y, en consecuencia, del gobierno deteriorada, débil, falta de credibilidad y carente del liderazgo que los cambios y las circunstancias que se avecinaban requerían. Esta mala imagen no sólo se daba a nivel doméstico sino que, más grave aún, era igual de negativa en lo internacional. Las múltiples y reiteradas denuncias hechas por los organismos no gubernamentales protectores de los derechos humanos, tanto nacionales como extranjeros, de una auténtica cascada de gravísimas arbitrariedades y violaciones de derechos fundamentales de todo género, pero de modo principal las relacionadas con las áreas policiacas del Estado (detenciones prolongadas e injustificadas, incomunicaciones, la tortura como método casi rutinario de investigación de los delitos para arrancar confesiones o delaciones a los otros supuestos copartícipes o implicados en delitos, etcétera), dieron rápidamente la vuelta al mundo y lograron conmover e incluso escandalizar a buena parte de la opinión pública internacional, sobre todo en países de América del Norte y de Europa occidental con los que el gobierno mexicano tenía especial interés en estrechar los vínculos políticos y económicos, para lo cual era esencial contar con una buena imagen. La respuesta de los sectores más sensibles de estos países fue el repudio y condena a dichas violaciones de derechos humanos y una acerba crítica al gobierno mexicano como responsable y principal protagonista de dicho ultrajes. Frente a esta situación de creciente malestar y crítica internacional contra el gobierno mexicano, se consideró necesario tomar medidas espectaculares, aparentemente drásticas y radicales, capaces de dar la vuelta al mundo, con la misma rapidez con que lo habían hecho las denuncias divulgadas por los organismos no gubernamentales defensores de los derechos humanos; pero también era imprescindible que dichas medidas fuesen capaces de impactar e incluso conmover a la opinión pública internacional tan adversa al gobierno mexicano. Se trataba de emprender una contraofensiva total, no sólo para contrarrestar la crítica negativa sino, más aún, para cambiar de manera radical, en un giro de 180 grados, la imagen del presidente mexicano y de su gobierno. Esta solución fue la creación de la Comisión Nacional de los Derechos Humanos". 15

En mi opinión, los órganos del Estado que tienen la responsabilidad de instrumentar el procedimiento para reformar la Constitución deben actuar de manera prudente y responsable en lo que a la creación de órganos constitucionales autónomos se refiere; es decir, resulta indudable que el Estado mexicano debe encarar con toda madurez jurídico-política las nuevas potestades y retos que ofrece nuestra complejísima realidad estatal y, cuando evidentemente estamos en presencia de una nueva responsabilidad pública, explorar de pri-

\footnotetext{
${ }^{15}$ El estado contra sí mismo, México, Noriega Editores, 1999, pp. 78-79. 
mera intención la posibilidad de que ésta pueda desarrollarse por alguno de los poderes tradicionales - estoy cierto que la vigencia del principio de división de poder se mantiene en el constitucionalismo contemporáneo intacta-; de lo contrario, bienvenida desde luego la posibilidad de que aquélla se despliegue precisamente a través de una autonomía a fin de armonizar - apoyado en la técnica legislativa y la práctica parlamentaria - la manera en que se comportan los poderes constituidos y las funciones que una determinada autonomía habrá de asumir. Sin embargo, cuando se trata de ponderar, evaluar o excluir una potestad jurídica desarrollada por algunos de los tres poderes de la Unión, debemos ser muy cautos al momento de proponer que ésta sea eliminada del conjunto de atribuciones de un determinado poder para desplazarla sin retorno a un órgano constitucional autónomo creado ex profeso.

Mucho alivia el hecho de que el procedimiento del artículo 135 Constitucional requiera la participación del Poder Legislativo Federal y el de las Entidades Federativas - con excepción del Distrito Federal-, a fin de que se analice y estudie en un genuino debate técnicoconstitucional organizado precisamente por las instituciones involucradas, si ante una nueva atribución del Estado Mexicano o la crisis de una ya existente, conviene crear una autonomía constitucional o bien, de lo contrario, realizar si fuere el caso, ajustes o enmiendas a una potestad que ya gravite en una poder tradicional.

México ha proyectado una serie de reformas constitucionales - conocidas por todos como estructurales - y, como consecuencia natural, para su debida instrumentación será indispensable acompasarlas de sus propias normas secundarias; insistimos pues en que debe privar la suficiente prudencia jurídico-política para no confundirnos y, en aras de una modernidad institucional en fuga, determinemos que lo más conveniente es crear autonomías por doquier a fin de que tales enmiendas constitucionales garanticen inequívocamente los resultados institucionales que se esperan de ellas. ${ }^{16}$

Finalmente, el hecho de que estas autonomías constitucionales se encuentren a la par de los poderes constituidos no implica, en modo alguno, que sus actos jurídicos se encuentren sustraídos del control constitucional. Su existencia como órganos del Estado mexicano los vincula indefectiblemente con la necesidad de que - como sucede con las funciones clásicas-, sus decisiones sean analizadas a partir del prisma del Poder Judicial de la Federación y las acciones de control constitucional que por mandato de nuestra Carta Política le corresponde a éste conocer y resolver a fin de que el actuar de aquéllos se ciña a lo que la Constitución les mandata, garantizándose así la consolidación del Estado de Derecho. ${ }^{17}$

\footnotetext{
${ }^{16}$ Apunta Valadés: "El número de entes tiende a aumentar. En el curso de los últimos doce meses fueron creados siete y reformados tres. En total, a la fecha, la Constitución regula trece: Instituto Nacional para la Evaluación de la Educación; Instituto Federal de Acceso a la Información; Instituto para proveer el servicio de radiodifusión; Instituto Nacional de Estadística, Geografía e Informática; Consejo Nacional de Evaluación de la Política Social; Banco de México; Comisión Federal de Competencia Económica; Instituto Federal de Telecomunicaciones; Comisión Nacional de Hidrocarburos; Comisión Reguladora de Energía; Instituto Nacional Electoral; Fiscalía General de la República, y Comisión Nacional de los Derechos Humanos", $O p$. Cit., nota 14 .

17 "Los actos de la Suprema Corte, realizados en interpretación constitucional, son los únicos actos de un poder constituido que escapan de la sanción de nulidad, lo que se explica si se tiene en cuenta que la Corte obra siempre, no sobre la Constitución, sino en su nombre". TENA RAMÍREZ, Felipe, Derecho Constitucional Mexicano, México, Porrúa, 1996, p. 16.
} 


\section{CONCLUSIONES}

La filosofía que inspira el principio de división del poder político descansa en la idea de que sólo el poder fragmentado representa una garantía para la libertad y la seguridad del individuo.

Así, en el Estado moderno el poder político es uno y se divide para su ejercicio en tres funciones clásicas: ejecutiva, legislativa y judicial. Esta es la premisa que está plasmada en nuestro artículo 49 Constitucional.

En la complejidad del Estado contemporáneo, la asunción de nuevas potestades o la resolución de alguna crisis jurídico-política vinculada a una función formal de algún poder, ha sido resuelta a través de la puesta en marcha del mecanismo jurídico del artículo 135 constitucional, el cual ha permitido crear diversos órganos autónomos que, sin responder formalmente a ningún poder constituido, se encuentran a la par de éstos y previstos desde la propia norma constitucional.

En forma reciente, se registra una expansión de estas autonomías reflejadas en nuestro texto constitucional. De ahí que se sugiere reflexionar y analizar la inercia que hemos descrito y que consiste en crear instituciones de esta naturaleza - desairando las funciones clásicas- a fin de aliviar los problemas inherentes al ejercicio del poder político.

Cierto es que el Estado de hoy exige asumir con toda solvencia ciertas responsabilidades que le son encomendadas bien por su agenda local, bien derivadas de compromisos de carácter internacional y para ello, el órgano autónomo se convierte en un paradigma institucional. Evidentemente, existen también supuestos en que el ejercicio de una potestad relacionada con un poder constituido puede reflejar un severo deterioro que pretenda ser salvado con la creación precisamente de una autonomía.

Empero, esto no debe convertirse en un "constitucionalismo de escape", por virtud del cual, toda crisis o parálisis relacionada con la arquitectura jurídico-política vigente en el país, deba ser resuelta irremediablemente por la creación ad infinitum de una autonomía constitucional, dejando en no pocas ocasiones, en plena orfandad jurídica a los poderes clásicos que vertebran la estructura del Estado.

Se debe tener presente que los actos jurídicos emanados de estas autonomías quedan sujetos al control constitucional que ejerce el Poder Judicial de la Federación.

BIBLIOGRAFÍA

BRISEÑO SIERRA, Humberto, El artículo 16 de la Constitución mexicana, México, UNAM, 1967.

CARBONELL, Miguel, Constitución, reforma constitucional y fuentes del derecho en México, México, Porrúa-UNAM, 2000. 
CARBOnELL, Miguel, [coord.], Diccionario de Derecho Constitucional, $3^{\mathrm{a}}$. ed., México, Porrúa-UNAM, México, 2009.

GINER, Salvador, Historia del pensamiento social, España, Ediciones Ariel, 1966.

GUDIÑO PELAYO, José de Jesús, El estado contra sí mismo, México, Noriega Editores, 1999.

HERNANDEZ RODRIGUEZ, Rogelio, Hacia un nuevo equilibrio en la relación de poderes, México, El Colegio de México, A.C., 2012, colección Los grandes problemas de México.

SALAZAR, Claudia. et al. "Disputan partidos órganos autónomos”, Reforma, México, D.F., año XXI, número 7,397, marzo 2014.

SÁNCHEZ GÓMEZ, Narciso, Distribución del poder público y el sistema presidencial, México, Porrúa, 2011.

TENA RAMÍREZ, Felipe, Derecho constitucional mexicano, 30ª ed., México, Porrúa, 1996.

VALADÉS, Diego, "La soberanía burocrática”, Reforma, México, D.F., año XXI, número 7,457, mayo 2014. 